\title{
CAMINHOS DE APRENDIZ DE PROFESSORA: PROCESSOS IDENTITÁRIOS EM UMA COMUNIDADE DE APRENDIZAGEM ONLINE
}

\author{
Rosana Maria Martins \\ Universidade Federal de Mato Grosso (UFMT), Rondonópolis - MT, Brasil \\ Rosa Maria Moraes Anunciato"* \\ Universidade Federal de São Carlos (UFSCar), São Carlos - SP, Brasil
}

RESUMO: Este artigo discorre sobre a constituição, em contextos colaborativos, da identidade docente de futuras professoras participantes de uma investigação sobre uma comunidade de aprendizagem online. Para este texto, buscou-se compreender como se expressam, nas narrativas, os indícios de constituição da identidade docente de licenciandas em formação. Os dados dessas narrativas autobiográficas mostraram como esse processo contribui para a constituição da identidade profissional docente e do desenvolvimento profissional, que se revelam em constante tensão, em um continuum, em que as experiências vivenciadas transcendem a polaridade teoria-prática e estão sempre vinculadas ao saber que emerge no próprio viver e fazer, a fim de significá-lo, problematizá-lo ou iluminá-lo.

Palavras-chave: Formação inicial em Pedagogia. Aprendizagem da docência. Identidade docente.

\section{TEACHER LEARNING PATHWAYS: IDENTITY PROCESSES IN AN ONLINE LEARNING COMMUNITY}

ABSTRACT:This article discusses the constitution of the teaching identity of future teachers in collaborative contexts, participant in an investigation about an online learning community. For this text, we seek to understand how they express, in the narratives, the evidences of the constitution of teaching identity of undergraduate women in formation. The data pointed out that the autobiographical narratives showed how this process contributes to the constitution of professional teaching identity and professional development that are disclosed in constant tension, in a continuum, in which the lived experiences transcend the theory-practice polarity, being these always linked to the knowledgethat emerges in the own living and doing, in order to mean it, problematize it or illuminate it.

Keywords: Initial training in Pedagogy. Teaching learning. Teaching identity.

\footnotetext{
"Doutora em Educação pela Universidade Federal de São Carlos (UFSCar).Professora Pesquisadora e Coordenadora do Curso de Pedagogia da Universidade Federal de Mato Grosso, Campos Rondonópolis (UFMT) CUR). Grupo de Pesquisa InvestigAção e Grupo de Pesquisa Estudos sobre a Docência: Teorias e Práticas. E-mail:<rosanamariamartins13@gmail.com>.

"* Doutora em Educação pela Universidade Federal de São Carlos (UFSCar). Professora Pesquisadora e Coordenadora do Programa de Pós-Graduação em Educação da Universidade Federal de São Carlos ((UFSCar). Grupo de Pesquisa Estudos sobre a Docência: Teorias e Práticas. E-mail:<rosa@ufscar.br >.
} 


\section{O FIO DA MEADA: AUTOBIOGRAFIAS DE FUTURAS PROFESSORAS}

Os estudos do Grupo de Pesquisa do CNPq "Estudos sobre a docência: teorias e práticas" têm mostrado a importância de problematizar a relação de professores com os conteúdos de ensino, considerando que a abordagem instrumental desse tema não possibilita alteração de práticas, no âmbito do projeto "Narrativas na formação inicial em Pedagogia e na formação contínua de professores iniciantes" (OLIVEIRA, 2011).

Nosso intuito centrou-se em narrativas autobiográficas de formação e em narrativas profissionais, especialmente nas marcas para a constituição da identidade docente. Instigadas por tal problemática, indagamos: Quais são as contribuições das narrativas autobiográficas para constituição da identidade docente na perspectiva das participantes do curso de extensão online-2013?

O olhar investigativo, de fiandeiras que alinhavam narrativas autobiográficas, aponta que esta investigação se pauta na pesquisa (auto)biográfica, com a perspectiva proposta por Câmara e Passeggi (2013, p.32), compreendendo, no âmbito do movimento internacional deste tipo de pesquisa, "que se interroga sobre os processos de biografização e o testemunho de indivíduos concretos e de ações concretas de grupos sócio-historicamente situados". Para as autoras, a investigação (auto)biográfica tem consolidado, gradativamente, a legitimidade de escritas subjetivas como fonte de pesquisa científica, a fim de produzir conhecimento humano.

Para nós, a autobiografia se alicerça enquanto pesquisa e formação e propicia, às interlocutoras desta investigação, partir da experiência que foram construindo no território iniciático e questionar os sentidos de suas vivências e de suas aprendizagens, fortalecendo a ação pedagógica para alcançar maior consciência do trabalho docente e de suas identidades como futuras professoras. Como afirmam Contreras e Pérez de Lara (2010, p.33), “o vivido deixa, em nós, um novo modo de olhar, de estar, de interpretar e de atuar".

A passagem de sujeito discente - em especial, daquele que está se graduando, principiando suas aprendizagens e seus estudos do "ser professor" - para docente é bem complexa, e cremos que as narrativas autobiográficas, ou seja, o recurso da escrita - em si mesmo, um processo reflexivo -, possa suavizar essa transição.

A pesquisa que apresentaremos se insere num contexto que envolve uma comunidade de aprendizagem online, composta por licenciandos no último ano de formação em Pedagogia, professores iniciantes dos primeiros anos do Ensino Fundamental (OLIVEIRA, 2011), pesquisadoras e pós-graduandas. 
Estudar a constituição da identidade docente de futuros professores por meio das histórias de escolaridade e de formação, assim como sua inserção profissional, é fundamental para o entendimento dos avanços e dos recuos que os auxiliam na aprendizagem de ser professor, pois a formação docente não se desenvolve a partir da licenciatura: ela é construída ao longo da vida. Estamos convictas de que os sujeitos, ao entrarem no decurso de formação, trazem consigo várias experiências que não podem ser descartadas da sua história. Ao narrar sobre si, no plano de sua interioridade, o sujeito estabelece associações livres, por trazer à tona e explicitar, com toda a força, a sua subjetividade (FERRAROTTI, 2010).

A preocupação em torno da constituição da identidade docente de futuras professoras, sob a lente das narrativas de formação e das narrativas profissionais, com sujeitos que participaram de um curso de extensão online, instiga-nos sobremaneira e nos leva ao aprofundamento desse objeto de estudo. Desse modo, o presente artigo busca compreender como se expressam, nas narrativas, os indícios de constituição da identidade docente de licenciandas em formação.

O exercício cotidiano dessa profissão atribui aos docentes variadas exigências, tarefas e competências, para responder às múltiplas demandas das situações de trabalho; dentre elas, destacamos: construção coletiva do projeto pedagógico da escola, capacidade profissional para tomar decisões e desenvolver importantes ações na própria escola, relacionamento entre escola e família, organização de espaços e tempos escolares, planejamento, formação continuada.

Assim, sentimo-nos convidadas ao mergulho neste campo de estudo, para evidenciara constituição da identidade docente, dando continuidade às pesquisas que buscam valorizar a transição de futuro professor a professor, prioritariamente, em seu território iniciático, ou seja, nos espaços-tempo da aprendizagem e da experiência de si (ALVES, 2014).

\section{FIANDO E TECENDO A CONSTITUIC̣ÃO IDENTITÁRIA DO SER PROFESSORA}

A constituição identitária tem sido enfoque de muitos estudos que, nos últimos anos, têm versado sobre formação de professores. Tal tendência se explica porque "uma compreensão mais aprofundada sobre o processo de constituição identitária docente pode levar a ações que resultem em melhores práticas de formação de professores e, por conseguinte, dos alunos da educação básica" (PLACCO; SOUZA, 2010, p.79). 
E ainda, segundo Moita (2000, p.114), “compreender como cada pessoa se formou é encontrar as relações entre as pluralidades que atravessam a vida", partindo do entendimento de que ninguém se forma no vazio e que o acesso ao modo como cada pessoa se forma é ter em conta a singularidade da sua história, compreendendo seu modo singular de agir, reagir e interagir com os seus contextos. Posto isso, um percurso de vida é, também, um percurso de formação. $\mathrm{O}$ processo de formação pode, assim, ser considerado como a dinâmica em que se vai construindo a identidade da pessoa. Movimento esse em que cada pessoa, permanecendo ela própria e reconhecendose a mesma ao longo de sua história, forma-se, transforma-se, em interação (MOITA, 2000, p.115).

A identidade docente se constrói no decorrer de um processo, no qual o indivíduo se apropria do sentido da sua história pessoal e escolar, sobretudo no contato do futuro professor com a prática profissional, cuja atividade diária marca trajetórias diferenciadas dessa identidade. Não deixa de ser uma ação complexa que requer tempo, para que seja possível refazer identidades, acomodar inovações e assimilar mudanças (NÓVOA, 2000).

Também para Marcelo (2009), a identidade docente é construída e transmitida. E se constitui pela interação entre o sujeito e suas experiências individuais e profissionais - no caso dos futuros professores, em suas primeiras experiências profissionais. Afirma ele: "é preciso entender o conceito de identidade docente como uma realidade que evolui e se desenvolve, tanto pessoal como coletivamente [...] e se caracteriza como um processo evolutivo, um processo de interpretação de si mesmo como pessoa dentro de um determinado contexto" (MARCELO, 2009, p.112). A identidade, portanto, não é algo que se possua desde sempre, mas ela se desenvolve ao longo do tempo. O que somos é algo que se forma e se transforma.

De acordo com Ciampa (2001, p.64), os pressupostos do conceito de identidade presumem que "o conhecimento de si é dado pelo reconhecimento recíproco dos indivíduos identificados através de um determinado grupo social que existe objetivamente, com sua história, suas tradições, suas normas, seus interesses, etc.”. Para ele, os aspectos dialéticos e contraditórios possuem uma intricada rede de representações que permeiam todas as relações, nas quais cada identidade reflete outra. Nessa direção, identidade é metamorfose, e denomina-se metamorfose a superação da identidade pressuposta.

Dubar (2005), ao estudar identidade, compreende que, ao generalizar, o sujeito identifica-se com aspectos comuns presentes em um grupo, e o que ele chama de identidade é pertença. E, ao trazer a 
reflexão da abordagem sociológica da noção da identidade, enfatiza ser necessário restabelecer a relação entre identidade para si e identidade para outro, no interior do processo comum que a torna possível, constituindo-se o processo de socialização. Esse sociólogo assegura que a identidade é como o resultado do processo de socialização, que abarca o encontro de sistemas relacionais (o sujeito é analisado pelo outro dentro dos sistemas de ação nos quais os sujeitos estão inseridos) e biográficos (que tratam da história, de habilidades e projetos do sujeito).

Esse conceito tem sido empregado por diferentes autores e reflete a complexidade e a diversidade teórica e metodológica dessa temática. Cardoso, Batista e Graça (2016, p. 373) enfatizam que as abordagens mais recentes acerca desse tema buscam, muitas vezes, desvalorizar ou desconstruir a visão essencialista do conceito, "enveredando pela desconstrução das práticas discursivas, pelo pósestruturalismo e pela pós-modernidade, encarando a identidade como produto do discurso, como inescusavelmente fragmentado, múltiplo e transitório (BENDLE, 2002)".

Para esses autores, a identidade é um fenômeno complexo que incorpora uma dimensão individual - entendida, normalmente, como núcleo da personalidade - e uma dimensão coletiva que remete o conceito de identidade para um nível de análise grupal ou coletivo. Embora essas dimensões tendam a ser tratadas de forma isolada, eles afirmam ser mais indicado considerar a sua interdependência: o individual necessita do reconhecimento do coletivo, e o coletivo necessita da capacidade de intervenção do individual.

Portanto, Cardoso, Batista e Graça (2016, p.386) partem do entendimento de que a (re)construção da identidade é um processo que transpassa "um nível passivo de não reflexividade, de aceitação e aquiescência, para um metanível de atividade reflexiva e crítica, impõe-se perscrutar quando e como se dá essa transformação, quer em relação ao nível pessoal, quer em relação ao nível profissional”. Sucede, então, que tal (re)construção não dispensa a prática comunicacional e requer a incorporação do pensamento reflexivo crítico e a intervenção ativa, legitimando-se como um processo dinâmico de interpretação e reinterpretação de experiências.

Sendo assim, acreditamos que as experiências vividas e narradas por futuras professoras em uma comunidade de aprendizagem que integra docentes iniciantes em interação colaborativa, desencadeiam e atribuem novos sentidos às próprias experiências, a fim de fortalecer o próprio processo de ensinar e de adquirir maior ressignificação do seu trabalho e da sua identidade profissional. Segundo Larrosa (2004, 2010), o que vamos dizendo de nós, atravessado pelos discursos dos 
outros sobre nós, colabora com a constituição de nossas identidades, pois os sujeitos se constituem pela linguagem.

Tal como Larrosa (2004), consideramos que nossa vida seja constituída pelo que nos atravessa e por nossas próprias experiências. Como nos adverte o autor, pelo que acontece conosco, pelas nossas experiências, isto é, pelo que sucede ao passarmos por esses ensaios, o tempo de nossas vidas é instituído. Passar pela experiência é sair transformado dela. Porém, é preciso considerar que a interpretação dessa prática pressupõe uma articulação temporal.

Para ele, o ser humano interpreta a si mesmo e, para essa autointerpretação, utiliza formas narrativas. É contando suas próprias histórias que o sujeito dá a si mesmo uma identidade. Obviamente, essa descrição identitária depende das histórias que são contadas. Acreditamos, então, ser na história de nossas vidas que os acontecimentos assumem uma ordem e um sentido. Como também é numa trama que construímos nossa própria continuidade ou descontinuidade, ao longo dos acontecimentos da nossa vivência.

Portanto,quando chegam à formação inicial, os futuros professores trazem consigo expectativas acerca da docência, provenientes de identidades sociais herdadas de um processo de socialização antecipatória, pelo qual começaram a construir uma identificação com a profissão antes de a iniciarem: "A aprendizagem para a docência é, pois, um processo complexo que cada indivíduo constrói e reconstrói de um modo singular considerando os processos de socialização e, em particular, as aprendizagens realizadas em contextos específicos" (CARDOSO; BATISTA; GRAÇA, 2016, p.386).

Souza (2012), no entanto, alerta que o papel da formação inicial é propiciar um cabedal teórico-prático que possibilite e impulsione a aprendizagem ao longo da carreira, favorecendo o desenvolvimento profissional crítico-reflexivo, em que o docente seja investigador de sua prática e que os conhecimentos sobre o ensino ${ }^{1} \mathrm{o}$ autorizem a lidar com a complexidade e as características específicas da docência. Tomando como referência tal argumento, faz-se necessário que o licenciando esteja apto a enfrentar situações adversas no cotidiano escolar, já que a formação concebida de modo instrumental, ou seja, como a mera incorporação de técnicas para a sua futura aplicação, não tem sido suficiente para sua futura atuação profissional. Como expõem Reali e Reyes (2009), é preciso compreender que tornar-se professor tem sido entendido como um continuum, isto é, um processo de desenvolvimento profissional, ao longo da vida toda.

E esse caminho não é feito sem tensões, conforme atestam Placo e Souza (2010): o processo de formação dos aprendizes e de suas identidades 
é atravessado por um movimento de tensão permanente, contínuo, fluido, com momentos de identificação que possuem dadas formas identitárias, sempre provisórias, mas constitutivas da maneira como esses futuros profissionais agem e pensam sobre o que fazem e vivem.

Portanto, as práticas educativas anteriores à formação acadêmica, vivenciadas e experienciadas pelos futuros professores na Educação Básica, são fontes relevantes de sua formação. O percurso de sua escolarização oportuniza o contato direto com a realidade da escola e do ensino, ou seja, com o contexto de sua futura prática profissional. Desse modo, as experiências escolares desse aspirante a professor, enquanto aluno, nos diversos níveis de ensino, configuramse como espaços e tempos imprescindíveis para a aprendizagem do trabalho docente, ou seja, para a constituição de sua identidade docente, e são um modo especial de se tornar e ser professor.

\section{A RODA A FIAR: TRAMA E TESSITURA DO PERCURSO INVESTIGATIVO}

Este estudo deu uma atenção especial para as licenciandas no último ano do Curso de Pedagogia que, em breve, irão vivenciar o período de inserção profissional. De acordo com Vaillant e Marcelo (2012, p.123), esse processo pode durar vários anos e é o período em que o professor principiante irá "desenvolver sua identidade como docente e assumir um papel concreto dentro do contexto de uma escola específica". É um percurso que não se dá como um salto no vazio entre a formação inicial e a formação continuada, já que há um caráter distinto e determinante para se conseguir um desenvolvimento profissional coerente e evolutivo.

Como já descrevemos, os estudos do Grupo de Pesquisa do CNPq "Estudos sobre a docência: teorias e práticas"apontam a importância de se problematizar a relação de professores com os conteúdos de ensino, considerando que a abordagem instrumental desse tema não possibilita alteração de práticas. Assim, o curso de extensão online, em 2013, alicerçou-se na perspectiva da construção de narrativas autobiográficas de formação, centrando-se em relatos de experiências significativas, de histórias de escolarização e de formação profissional e, ainda, em declarações que envolveram experiências com as disciplinas Língua Portuguesa e Matemática.

Cabe ressaltar que, "para cumprir tal finalidade, na nossa perspectiva, o grupo colaborativo realiza essa dimensão da formação", pois, como afirma Oliveira (2011, p.295), cada participante tem voz, apresentando sua perspectiva experiencial narrada por si mesmo. 
Há uma validação do seu conhecimento sobre o ensino, na medida em que seus saberes são considerados, partilhados na comunidade de aprendizagem online, refletidos; oferecem oportunidades para o estudo de histórias pessoais, em termos de passado e presente; e oportunizam o planejamento de experiências profissionais futuras.

Ferreira e Silva (2014, p. 39) esclarecem a relevância de se criarem comunidades de aprendizagem online. De acordo com eles, "essas comunidades facilitam a comunicação entre os participantes, tendo em vista um aprendizado colaborativo, em que cada ator educativo pode contribuir e é convidado a fazê-lo, para a potencialização do trabalho do outro e do seu próprio trabalho".

O curso de extensão, com 60 vagas, contou com a carga horária de 120 horas e duração de sete meses (de 06 de maio de 2013 a 30 de novembro de 2013). Inicialmente, recebeu 718 inscrições no Portal dos Professores, e foi necessário fazer uma triagem para adequar a quantidade de inscrições à quantidade de vagas ofertadas. Muitos não se encaixavam no perfil divulgado no Edital e, consequentemente, foram eliminados. Devido ao grande número de candidatos que se enquadravam no perfil do curso, decidiu-se ampliar o número de vagas e selecionar os alunos do último ano do curso de Pedagogia e os professores com o menor tempo de experiência, mas, mesmo assim, alguns ficaram em uma lista de espera. No total foram selecionados 74 participantes (34 licenciandos em Pedagogia e 40 professores iniciantes), dos quais $27^{2}$ concluíram o curso.

Entre as futuras professoras e os professores iniciantes há uma aproximação temporal, já que uns estão prestes à inserção profissional e outros estão, no máximo, há três anos na docência; portanto, próximos do tempo de estudantes. A preferência por esse público é de extrema relevância, pois os momentos de formação acadêmica e inserção na carreira profissional são muito angustiantes e, ao mesmo tempo, repletos de expectativas. A falta de apoio e de acompanhamento favorece o sentimento de descrença em relação à docência e, até mesmo, o abandono da profissão. Por isso, o curso formativo online teve a intenção de conhecer o que esses participantes dizem, pensam, sentem e fazem. Isso parece, ao grupo, muito positivo, pois a formação por meio do Ambiente Virtual de Aprendizagem (AVA) pode favorecer não apenas a comunicação de todos os componentes com os formadores, mas também o acesso a outros recursos online disponíveis, além de permitir a configuração de "diferentes cenários formativos que combinados podem proporcionar uma aprendizagem mais significativa” (VAILLANT; MARCELO, 2012, p.204). 
Por meio da Plataforma Moodle, ${ }^{3}$ foram realizadas atividades de formação online: fórum de apresentação, fórum de dúvidas, fórum de discussões, produção de narrativas e discussões em chat, agendadas previamente.

Compreendemos o fórum online como uma ferramenta de aprendizagem e de formação que possibilita a comunicação e a interação de conhecimentos, aprendizagens, dúvidas, curiosidades etc. entre os participantes do grupo. Por conseguinte, é considerada uma atividade assíncrona, pois cada uma realiza conforme sua disponibilidade de tempo e de forma independente dos seus pares, não sendo necessário que todos estejam online para que a participação ocorra simultaneamente. $\mathrm{Na}$ comunicação assíncrona, cada sujeito, na sua individualidade, pode expressar e produzir saberes, desenvolver suas competências comunicativas, contribuindo e construindo a comunicação e o conhecimento coletivamente (SANTOS, 2003, p.11).

A partir de leituras e/ou questionamentos dos professores formadores responsáveis pelo curso, dos colegas e de outros participantes do grupo colaborativo, os integrantes foram colocados em situação de reflexão e ampliação desses contextos, a fim de identificar a interdependência de fatores socioculturais que deram origem a combinações específicas na história de vida e de formação profissional $^{4}$ de cada sujeito. Assim, o processo de aprendizagem, neste curso de extensão online-2013, esteve apoiado nas colaborações entre os participantes e resultou, portanto, na constituição de uma comunidade de aprendizagem online (KENSKI, 2008).

O curso contou com o desenvolvimento de quatro etapas: a primeira foi o período de ambientação das participantes; a segunda, denominada "Formação", foi composta por atividades que buscavam o relato de experiências significativas dos anos de escolarização dos cursistas, acompanhado de fórum de discussão; na terceira e na quarta etapas, denominadas, respectivamente, "Narrativas-Língua Portuguesa" e "Narrativas-Matemática", os integrantes conseguiram discutir questões sobre essas áreas através de fóruns e escrita de narrativas. E, para concluir, a última tarefa seria escrever uma narrativa sobre o próprio processo formativo durante o curso, na qual puderam refletir a importância dele para a constituição de sua identidade docente.

Para a pesquisa de doutoramento (MARTINS, 2015), foram selecionadas todas as futuras professoras que concluíram o curso de extensão online-2013. A escolha por essas participantes foi orientada, prioritariamente, pelo objetivo geral da pesquisa, que buscava compreender como se expressam, nas narrativas, os indícios de constituição da 
identidade docente de licenciandas em formação e o modo como se dá, a posteriori, com a inserção de uma professora na docência, o movimento do processo formativo de sua identidade profissional.

Apoiadas por Nacarato e Passeggi (2011, p. 2), partimos do pressuposto de que, se as experiências provocam mudanças identitárias, é possível, durante a formação inicial, colocar os aprendizes no movimento de olhar para si mesmos, para seu processo de formação atual e anterior, partindo de situações de reflexão e problematização dos contextos históricos e políticos nos quais eles foram e estão se constituindo; pôr em discussão determinadas práticas; e projetar-se para outras.

Em consonância com essa forma de compreender o processo identitário, neste trabalho, a narrativa autobiográfica de formação é, potencialmente, um recurso auxiliar à constituição da identidade docente, pois, neste tipo de escrita, "o ser em formação só se torna sujeito no momento em que a sua intencionalidade é explicitada no ato de aprender e em que é capaz de intervir no seu processo de aprendizagem e de formação para favorecê-lo e para reorientá-lo" (JOSSO, 2010, p.78-79).

Segundo Ferrarotti $(2010,2014)$, a escrita da narrativa abre espaços e oportuniza, aos sujeitos em processo de formação, falar-ouvir e ler-escrever sobre suas experiências formadoras e, assim, descortinar possibilidades sobre a formação por meio do vivido. Conforme Souza (2007b, p.69), "a construção da narração inscreve-se na subjetividade e estrutura-se num tempo, que não é linear, mas num tempo da consciência de si, das representações que o sujeito constrói de si mesmo".

Nacarato e Passeggi (2011, p. 3) esclarecem que a narrativa contribui tanto para o leitor quanto para o produtor, já que, no ato de sua escrita, o sujeito não apenas precisa se lembrar dos fatos passados, mas também terá que construir um cenário, uma trama na qual a história se passa, incluindo personagens e ações. E precisará, ainda, pensar em quem será o leitor dessa história. "Todo texto pressupõe um leitor. $\mathrm{E}$ mais, no momento da escrita há todo um processo de reflexão sobre a experiência a ser narrada. Esse é o momento em que se atribui sentidos e significados ao que se faz" (NACARATO; PASSEGGI, 2011, p.3).

Importa, aqui, considerar Larrosa (2004, p.20), que enfatiza: "o ser humano é um ser que interpreta a si mesmo e, para essa autointerpretação, utiliza-se, fundamentalmente, de formas narrativas". Segundo esse autor, é nesse sentido que se pode pensar a relação entre a misteriosa entidade que é o sujeito (autoconsciente e também, intersubjetivo; pessoal, mas também social, histórico, cultural etc.) e esse quase onipresente gênero discursivo que é a narrativa. Assim, para Larrosa (2004, p.17), "o que acontece enquanto 
experiência só pode ser interpretado narrativamente. É na história de nossas vidas que os acontecimentos ganham uma ordem e um sentido". Lima, Geraldi e Geraldi (2015. p.19) corroboram esse entendimento, ao esclarecerem que "o acontecimento é aquilo que se passou, enquanto o sentido da experiência se encontra naquilo que é narrável de um acontecimento, o que nos passou, nos (co)moveu".

A partir desse contexto, optamos pela metodologia interpretativo-hermenêutica, segundo a qual cada parte adquire seu significado em função do todo e, desse modo, o informe da investigação como totalidade (do que foi colhido) depende - por sua vez - do significado de cada parte, centrado no esforço em dar sentido ao vivido/recolhido. Para tanto, assumimos a análise interpretativo-compreensiva, como expôs Souza (2014), em que partimos da singularidade das histórias e das experiências contidas nas narrativas individuais e coletivas dos sujeitos participantes dos processos de pesquisa e/ou formação, a fim de compreender o relato de cada futura professora sobre suas experiências vividas e sobre as lembranças que se tornaram públicas, depreendendo as marcas que evidenciam a construção da identidade docente.

Os excertos que traremos neste artigo foram retirados das atividades realizadas na etapa "Formação" (AI) do curso de extensão online. As atividades previstas para essa fase foram intituladas de: "Relatos de experiências significativas" (AI-1), "Leitura de narrativas sobre a escolarização e discussão em fórum" (AI-2), "Produção textual - Texto dissertativo" (AI-3), "Fórum de discussão: experiências vividas na formação inicial e no início da carreira docente" (AI-4), "Fórum narrativa de uma professora iniciante" (AI-5), "O que todo professor iniciante precisa saber" (AI-6), "Documento síntese do fórum 'O que todo professor iniciante precisa saber"' (AI-7). E, para finalizar essa etapa, realizou-se um chat.

É importante informar que, ao longo das análises acerca da constituição da identidade docente, as narrativas autobiográficas serão ordenadas e reordenadas, nem sempre respeitando e seguindo a ordem cronológica original, porque, no movimento da escrita narrativa, é comum o ir e vir das futuras professoras, ao relatarem - sobretudo nas trocas que realizaram durante o curso de extensão online-2013 os fatos que mais marcaram sua trajetória. Em muitos casos, houve a necessidade de limpar "vícios de linguagem" e alguns erros da escrita, a fim de que o relato propiciasse melhor entendimento ao leitor. As protagonistas desta pesquisa, em suas narrativas, citam nomes de seus professores e de locais, aos quais atribuiremos letras aleatórias do alfabeto para identificá-los, resguardando suas identidades. 
A seguir, apresentamos as análises das narrativas autobiográficas de formação das futuras professoras, a fim de se compreender como cada participante vai construindo/reconstruindo sua identidade docente, tendo como travessia de encontro uma comunidade de aprendizagem online.

\section{EXPERIÊNCIAS NARRADASE REVELADAS NA COMUNIDADE DE APRENDIZAGEM ONLINE}

Propusemo-nos a escutar e a entrar em contato com as protagonistas desta pesquisa como pesquisadoras atentas não somente aos fatos, às histórias em si, mas também aos pontos de vista, aos interesses, às aspirações, aos desejos, às razões, aos sentidos, aos sentimentos, aos significados - enfim, buscamos encontrar relação e aproximação com a experiência própria de cada futura professora e também com a experiência de outros sujeitos trazida por elas, o que nos permitiu captar o sentido que dão ao vivido, às aprendizagens e aos saberes da prática educativa que as conduzem a serem professoras. Nosso propósito não é descrever e reconstruir histórias escolares e de formação presentes nas narrativas de formação, mas, sim, assumir postura compreensiva, colocando-nos à disposição para alargar o sentido educativo e viver novas experiências, na acepção trazida por Contreras e Pérez de Lara (2010, p.82): "escrever é fazer experiência e não só relatá-la”.

Seguem alguns excertos que apontam os indícios da constituição da identidade docente a partir das experiências vividas por Juma, Marta, Paula, Laís, Sofia, Stella, Laura e Carolina, nomes fictícios das futuras professoras no curso de extensão online 2013.

\section{AS MARCAS QUE ME PASSAM NA INSERÇÃO PROFISSIONAL: NA VOZ DAS LICENCIANDAS...}

As futuras professoras narram episódios que envolvem os familiares em seus percursos escolares. No caso de duas cursistas, as marcas domésticas trazem a presença positiva dos familiares em suas vidas. São narrações de forte valor sentimental, mas que também apontam aprendizagens.

[...] ouvindo aquelas coisas [histórias] que nos levavam a outro mundo. [...] todo dia meus pais vinham com uma nova história, uma nova poesia, um novo verso... Meus pais não sabiam ler e nem escrever, porém eram possuidores de uma sabedoria invejável.

[...] adquiri os meus primeiros conhecimentos através do ouvir, do falar, das ações, gestos e convivência, ou seja, o conhecimento vulgar, do dia a dia. (Juma, AI-1/2013) 
Juma (AI-1/2013) expõe sobre sua infância, conta que nasceu na zona rural, onde viveu "seus primeiros seis anos", os quais, segundo ela, foram os mais especiais de sua existência, pois

\begin{abstract}
tudo parecia mágico, brincávamos [ela, os irmãos e os colegas] de ciranda cirandinha, atirei o pau no gato, passa o anel, esconde-esconde, peteca; os caroços de manga, sabugo de milho e as cascas de melancia se transformavam em bonecas, as latas de óleo em carrinhos, os cipós das árvores que ficavam na beira do rio eram nossos balanços, as catanas de coqueiro mais pareciam jetski, descendo colina abaixo com nós dentro... Fazíamos gangorras embaixo dos pés de manga que ficavam na porta da casa [...], banhávamos diretamente no rio onde as águas eram puras e cristalinas cheias de lambaris que pareciam estar brincando conosco. Andar de cavalo pelas matas e estradas nos dava a sensação de liberdade absoluta longe de qualquer ação violenta por parte do homem [...].
\end{abstract}

Essa narrativa expõe a convivência com irmãos e amigos, o grau de escolaridade dos pais, a profissão deles e a situação econômica. Segundo Dominicé (2010, p.87), tudo que é citado faz parte do processo de formação, e a família "é o lugar principal dessas mediações. Os pais são objeto de memórias muito vivas. Estabelecese com cada um deles uma relação particular, que vai, por vezes, mostrar-se determinante na orientação escolar ou profissional”.

Seguindo com as narrativas, os excertos de Paula, Juma e Marta dão evidências de quanto as normas e a rigidez as afetaram, sobremaneira, na Educação Primária/Ensino Fundamental. Paula (AI-1/2013), ao relatar um episódio transcorrido na quarta série, quando ficou em recuperação, menciona: "minhas experiências escolares na 4. " série foram as mais marcantes na minha vida".

Para Juma (AI-1/2013), "o som estridente da campainha soando" antes das aulas iniciou a lhe causar "estranheza e medo". Marta (AI-1/2013) relembra as saias do uniforme no período da ditadura que, padronizadas, deveriam ficar abaixo dos joelhos; e o uso de canetas e de cadernos espirais, que era reservado somente para o segundo grau.

A esse respeito, é oportuno mencionar novamente Larrosa (2004, 2010), ao sinalizar que a experiência é o que nos passa. E Contreras e Pérez de Lara (2010, p.25) complementam: "neste o que nos passa, o que me passa, há sempre um sujeito que vive, se expressa, padece ou goza de um corpo sexuado", pois toda experiência, por nascer precisamente do vivido, é a experiência de um corpo e do corpo.

Sofia e Laís também relembram acontecimentos provenientes de normas e rigidez de ocorrências no Ensino Médio. Sofia (AI$1 / 2013$ ) relata a crise de urticária devido à pressão do vestibular, e Laís (AI-1/2013) recorda a média escolar no período da ditadura militar no Brasil. Embora tivessem estudado em períodos educacionais diferentes 
- Laís, no período da ditadura, marcada pelo ensino tradicional e Sofia, na época da implantação da LDB 9394/96, assinalada por um ensino de características progressivas -, tais narrativas apontam traços da educação tradicional, em que imperavam, segundo Bordenave (1999), o hábito de tomar notas e memorizar; a passividade do aluno e a falta de atitude crítica; o profundo "respeito" às fontes de informação, fossem elas professores ou textos; a distância entre teoria e prática; a tendência ao racionalismo radical; a preferência pela especulação teórica; a falta de "problematização" da realidade.

Os episódios significativos descritos pelas licenciandas revelam sua relação com seus professores em acontecimentos que envolviam os colegas de sala de aula. Paula (AI-1/2013) relata sua má recordação, centrada na postura de um professor que privilegiava aprendizagem sem questionamentos e, por sua atitude, provocava tensão nos alunos. Ela, porém, relembra que, ao passar pelo período de recuperação, pôde ter esta imagem desconstruída já que as aulas não foram ministradas pelo professor titular.

Para minha surpresa, não era o professor de cabelos brancos que estava na escola para recepcionar os alunos da recuperação e sim uma jovem professora de feições simpáticas, que já nos recebeu com abraços e muito carinho [...] A partir da primeira aula da recuperação, queria todos os dias ir para escola, era gostoso aprender com aquela professora (recuperação). (Paula, AI-1/2013)

A experiência da recuperação fez-se abrir um novo horizonte em minha vida, onde aprender que pode ser divertido. Onde ler não é um ato de obrigação e sim um ato de satisfação, pois um bom livro nos leva a conhecer novas culturas, novos povos, novos mundos, abrindo um leque de aprendizagens significativas que farão parte de nossas vidas para sempre. (Paula, AI-1/2013)

A prática pedagógica da nova professora, valorizando a descoberta pela construção do conhecimento, e a "transação" (JOSSO, 2004) professor-aluno foram fatores preponderantes para Paula ser impelida a buscar novas aprendizagens.

Paula mostra uma identidade em movimento, em metamorfose, superando a identidade pressuposta que lhe foi dada (CIAMPA, 2001). Em sua narrativa, ela informa que, depois da recuperação, voltou a ter aulas com o professor dos cabelos brancos, porém, a partir da experiência vivida, "a escola não era mais a mesma, graças à jovem professora" substituta, que, inclusive, levou Paula a mudara imagem de docente que ela havia construído (Paula, AI-1/2013).

$\mathrm{Na}$ atividade que solicitava relato sobre as lembranças das aprendizagens matemáticas também são apontadas, desde as práticas pedagógicas na disciplina, facilidades e dificuldades - essas últimas, 
circunscritas à não assistência pelo professor. Os excertos de Stella (AI-1/2013) permitem visualizar os altos e baixos que ela estabeleceu com a matemática, pela falta de comprometimento e de interatividade com alguns professores:

[Quinta série] Voltei a ter dificuldades em matemática, principalmente nas partes de aritmética e geometria.

[Sexta série] Nesse ano, alguns problemas com a matemática começaram a ser resolvidos. O professor nos ajudava mais, e focava nos principais problemas da sala.

Na sétima série, os problemas com a matemática voltaram, principalmente, na parte de aritmética, a professora era bem desligada, não ligava muito para nossas dificuldades, e por isso formamos grupos de estudos, para trabalharmos essas dificuldades.

[Oitava série] A matemática nesse ano foi bem tranquila, pois retomamos todos os conteúdos que vimos desde a quinta série [...]. Então as dificuldades que tive durante esses anos foram sanadas, e consegui compreender melhor a aritmética e a geometria.

[Ensino médio] Foram muitos os ensinamentos que esse professor [matemática] nos passou, uma coisa que tirei dessa experiência é que, enquanto professor, podemos ampliar o modo de pensar de nossos alunos, podemos estimulá-los a buscar cada vez mais conhecimentos. Devido à prática desse professor, mudamos nosso jeito de ser e pensar, começamos a nos dedicar cada vez mais ao estudo e buscar novas formas de conhecimento. Eu, em particular, comecei a buscar novos conteúdos e novas aprendizagens.

Essa sequência de episódios, trazida por Stella em sua narrativa, exemplifica a importância do olhar atento do professor às inibições de aprendizagem dos estudantes, para determinar as intervenções necessárias a fim de sanar as dúvidas no processo ensino-aprendizagem. Quando esse fator não é considerado pelo docente, possivelmente, dois caminhos são trilhados pelo aprendiz: o fracasso na aprendizagem pode levar ao abandono da escola ou à busca por quem possa ajudá-lo a entender o conteúdo. No caso de Stella, na sétima série, ela e os colegas formaram grupos de estudos para compreender melhor a matéria.

Os excertos de Stella evidenciam um movimento de constituição de identidade docente, em que ela descobre, a partir da prática do professor, como deseja projetar sua prática futura. Vemos, nesse processo, o ato de pertença descrito por Dubar (2005), já que a aprendiz se identifica com as práticas pedagógicas do professor e adere a essa identidade.

É significativo perceber que os processos de rememoração, tendo as narrativas como experiência formadora, o ato de lembrarnarrar, remetem as licenciandas exatamente ao que Souza (2007a, 
p.17) descreve, ou seja, às recordações-referências em suas dimensões simbólicas, concretas, emocionais, projetando-as a uma nova identidade, justamente "porque a utilização dos recursos experienciais engendra marcas acumuladas das experiências construídas e de mudanças identitárias processadas nas itinerâncias individuais". Esses movimentos de constituição da identidade docente são perceptíveis em Stella (AI-1/2013), ao projetar a professora que deseja ser:

Esse relato de experiência me relembrou diversos momentos de minha formação que até então estavam adormecidos; pude relembrar minhas dificuldades, principais aprendizagens e, principalmente, momentos cruciais que me fizeram escolher a profissão docente e como a prática pedagógica de um só professor [matemática no terceiro colegial] me moldou e me mostrou que tipo de profissional quero ser.

A influência desse professor foi tão intensa, que ela chegou a afirmar: "O terceiro ano do colegial foi o que mais me marcou. [...] tive certeza absoluta de que queria ser professora, devido à prática de um professor, [...] meu professor de matemática. Nunca havia tido um professor como ele" (Stella, AI-1/2013).

Esta licencianda, em muitos momentos, reafirma seu desejo de ser professora e segue apontando aonde vai realizando a aprendizagem para o exercício da função docente, demarcando seu processo de vir a ser professora: "A experiência no programa [PIBID] está me ajudando muito e me mostrando qual o tipo de profissional que quero ser" (Stella, AI-6/2013).

Seguindo com a escuta, a tomada de consciência sobre a docência é perceptível nas narrativas de formação que as futuras professoras trouxeram em seus relatos de experiência. Com Sofia (AI1/2013) e Carolina (AI-1/2013), é possível visualizar a influência do curso de Pedagogia, corroborando o entendimento do que acontecia e acontece na escola, ajudando-as a ressignificar suas dúvidas a respeito da profissão docente, em relação à escola, às disciplinas, como se vê nos excertos a seguir:

É muito difícil rememorar episódios em especial; quando penso em toda essa trajetória escolar, ficam vivas as relações de amizade que tive, as brincadeiras, fugas, as descobertas... Lembrar-me de tudo isso traz um pouco de sofrimento, também, porque nem todos os momentos foram bons, houve muitas rupturas que eu trouxe comigo, muitas dúvidas em relação à escola. (Sofia, AI-1/2013)

Para mim, a matemática também sempre foi um pesadelo, porém, como já disse anteriormente, minha visão sobre ela tem mudado ao longo do curso de Pedagogia. (Carolina, AI-4/2013)

No caso de algumas licenciandas, os modelos e as rupturas (contramodelos) vêm de seus antigos professores, embora sinalizem 
marcas positivas e sejam, assim, referências e fontes de aprendizagens. Esses dados convergem com o relatado na dissertação do Martins (2012), em que os modelos de docência então vivenciados ao longo da trajetória de estudante, suas recordações, sua identificação, sua diferenciação, subsidiam, auxiliam e alicerçam a constituição dessa identidade, pois agem tanto na repulsa por um modelo de professor e, daí, na busca por sua superação, quanto na admiração pelos bons profissionais e, por isso, sua imitação. Isto posto, "no processo de análises, reconstrução e reflexões, os licenciandos vão construindose docentes e, nesse movimento, a identidade vai se constituindo e se refazendo a cada passo que os licenciandos avançam na vida e nos estudos da formação docente" (MARTINS, 2012, p.81).

Os excertos vão dando pistas de que o desejo de fazer diferentemente do que viram, viveram ou ouviram, isto é, experienciaram, coloca essas futuras professoras em condições de ressignificar percursos e processos vividos e narrados, em que tais lembranças acabam sendo rememoradas e/ou reconstruídas e sinalizam perspectivas futuras, como nos contaram Laura e Carolina.

Essas experiências que vivi e que foram significativas na minha formação possibilitaram e abriram caminhos para a minha constituição enquanto pessoa e futura profissional da educação; penso que elas [...] se tornaram marcantes pela intensidade com que aconteceram e pelos significados e aprendizagem de que elas estavam compostas. (Laura, AI-1/2013)

[...] posso dizer que minha formação ainda não está completa, pois, apesar de ter aprendido muitas coisas na escola, considero que ainda tenho muito que aprender, principalmente, porque serei uma professora, ou seja, estarei todos os dias ensinando a meus alunos algo novo, e isto quer dizer que tenho sempre que buscar novas formas de ensinar os conteúdos pretendidos e aprender outros conhecimentos, pois, assim como a sociedade, os alunos de hoje não serão os mesmos de amanhã. (Carolina, AI-1/2013)

Essas passagens descritas por Laura e Carolina apontam a construção da identidade docente dentro de um continuum. Tais afirmações também são ratificadas por Placco e Souza (2010), ao observarem que a construção da identidade é movimento, é atemporal e constante. A capacidade do professor para transformar o conhecimento que tem do conteúdo em formas de ação pedagógica é perceptível na narrativa autobiográfica de Carolina, ao expor a necessidade de "buscar novas formas de ensinar os conteúdos pretendidos e aprender outros conhecimentos".

Outro fator que se mostrou presente nas narrativas de formação foi a releitura de si e do processo de escolarização, desencadeada pelas trocas realizadas, desde as primeiras atividades do curso de extensão online -2013. 
Penso que, dessas narrativas, o que fica como reflexão é que nossa trajetória como alunos e as experiências boas e más que tivemos com nossos professores nos marcaram muito, e hoje de certa forma nos ajudam a aprimorar técnicas que deram certo conosco e descartar aquelas que não tiveram êxito, sempre procurando o melhor para nossos futuros alunos, pensando naquele cidadão que queremos formar. (Marta, AI-2/2013)

Para terminar, quero deixar um questionamento para os demais colegas, o qual já foi mencionado pela professora L. Será que queremos que nossos alunos estejam ocupando apenas os melhores lugares ou também queremos que eles estejam preparados para a vida, para lutar por seus direitos e por um mundo melhor? Faço este questionamento, pois na maioria das narrativas vemos que o mais importante para os autores e para mim também foi de estar no grupo dos melhores, mas, assim como eles, também percebi que não é só isso que fará a diferença em nossa vida, mas sim uma formação baseada na reflexão. (Carolina, AI-2/2013)

A reflexão sobre as experiências escolares e de formação vai evidenciando que as futuras professoras são capazes de pensar, sistematicamente, sobre as práticas vivenciadas durante suas trajetórias enquanto alunas, aprender com as experiências e projetar novas ações para a docência no porvir. Os dados dão indícios de como elas vão constituindo sua identidade docente, em um percurso cujos movimentos não são fixos; são provisórios, e essa provisoriedade as impele a agir, a pensar e a escolher o modo de virem a ser professoras.

As trajetórias vivenciadas e descritas nas narrativas constituemse em um elemento central para a compreensão do aprender a ensinar e colaboram, segundo Flores (2009), com o modo como a identidade docente vai se (re)construindo. Nóvoa (2000) salienta que a identidade se constrói ao longo de um processo complexo das diversas maneiras de ser e de estar na profissão; Marcelo (2009) afirma que a identidade docente se caracteriza de modo evolutivo, envolvendo um movimento autointerpretativo como sujeito dentro de um determinado contexto; e, segundo Josso (2004), a formação acentua o inventário dos recursos experienciais acumulados e das transformações identitárias que envolvem, dentre tantas outras, a capacidade de orientação aberta ao desconhecido.

As futuras professoras, em suas narrativas, integram a história individual, cultural e social em que transitaram e transitam, articulando, na constituição de suas identidades docentes, os atos de atribuição (do outro para si) e de pertença (de si para o outro), em um movimento tensionado, contínuo e permanente. Os excertos que narram sua trajetória escolar e formação assinalam os movimentos de atribuição e de pertença, descritos por Dubar (2005), do passado e do presente, suas histórias e suas representações, em identidades que se mostram abertas às novas aprendizagens. 
Sendo assim, o apoio ao iniciante é visto também como fundamental, já que esse período é marcado, como apresenta Nóvoa (2014), por angústias, tensões e aprendizagens, conforme já ratificados nos trabalhos de André (2013); Palachi (2011); Reali, Tancredi e Mizukami (2008); Simon (2013, 2014); Vaillant e Marcelo (2012); e Veenman (1984 apud MARCELO, 1999), dentre outros. Portanto, há de se pensar em políticas que realmente colaborem com a indissociabilidade de teoria e prática, a fim de que os alunos percebam a relevância de compreender a teoria, para que ela tenha sentido na práxis pedagógica, pois, quando narram a prática, esses futuros professores clamam pela teoria.

Esta insegurança [início da carreira] nos traz dificuldades em lidar com situações que foram ou não discutidas durante todo o nosso curso, pois na maioria das vezes não conseguimos aplicar o que as teorias dizem na realidade de nossas escolas. (Carolina, AI-3/2013)

O discente de pedagogia precisa estar em constante reflexão acerca de teorias e métodos de aprendizagem, bem como vivenciá-los na prática. (Paula, AI-3/2013)

[...] são tantas as dificuldades e obstáculos encontrados que a impressão é de que a teoria estudada em sala de aula (Universidade), quando defrontada com a prática, de nada serviu. (Juma, AI-3/2013)

De certa forma, esse contato direto com a realidade da escola e do ensino, ou seja, com o contexto de suas futuras práticas profissionais, oportuniza "olhar de novo" e "colocar-se em jogo em primeira pessoa", o que, de certa maneira, já as afetou, como bem sinalizam Contreras e Pérez de Lara (2010, p.118), permitindo "um novo olhar em cada uma dessas vivências".

Contreras e Pérez de Lara (2010) se dizem convencidos de que a compreensão do processo educativo, a partir da perspectiva da experiência, coloca-nos em contato com as dimensões da prática e das relações educativas e, ainda, com as dimensões do fazer pedagógico de educadores e educadoras que, com suas qualidades especiais, incorporam um saber nem sempre formulado, nem exatamente teórico ou facilmente teorizado, mas um saber imprescindível como saber pedagógico e, segundo eles, "provavelmente o próprio saber pedagógico” (CONTRERAS; PÉREZ DE LARA, 2010, p.22).

É importante destacar os trabalhos de Mizukami et al. (2003), Rodgers (2002) e Zeichner (2008, 2014), por trazerem discussões profícuas acerca da relevância da reflexão sobre a ação pedagógica e, consequentemente, da teoria e da prática. Zeichner, Saul e DinizPereira (2014) chamam a atenção para o fato de que é preciso reconhecer um modelo de formação que distinga a experiência e o conhecimento que existe na escola. 
Laís (AI-6/2013) crê que "a universidade não consegue ensinar tudo que o professor iniciante necessita saber”. Já Stella clama pelo apoio das universidades aos professores iniciantes, no momento de inserção na carreira profissional.

Acredito que a universidade deveria dar um respaldo e apoio para os futuros professores, explicar como é o processo de inserção do professor iniciante na rede de ensino. [...]

Acho uma pena os professores dentro da Universidade desconhecerem esse processo, acredito que pelo menos a coordenação do curso deveria dar algum suporte/apoio nesse aspecto, acho que isso pode auxiliar muito os professores iniciantes. (Stella, AI-5/2013)

As narrativas autobiográficas dos indícios de constituição da imagem docente deixam pistas de que a construção da identidade docente é caracterizada pelo retorno das licenciandas ao percurso de sua escolarização e formação inicial, em que ficam evidenciados os ritos, as normas, a rigidez, os episódios significativos da relação entre docente e aluno e entre aluno e aluno; as lembranças provenientes da Língua Portuguesa e da Matemática; o choque com o "novo" contexto escolar e, ainda, a opção pelo curso de Pedagogia, por ser professora. Desse modo, as experiências escolares dessas aspirantes a professoras, enquanto alunas, nos diversos níveis de ensino, configuram-se como espaços e tempos importantes para a aprendizagem do trabalho docente, ou seja, para a constituição da identidade docente e de um modo especial de se tornarem e serem professoras.

\section{CONSIDERACִÕES FINAIS: IDENTIDADES EM CONTINUUM}

Os dados analisados, provenientes das narrativas de si, de questões e comentários que se seguiram nos fóruns de debates, ajudam-nos a compreender o processo reflexivo individual e coletivo deflagrado no grupo do curso de extensão online-2013. As discussões serviram como fonte de dados para a compreensão de raciocínios argumentativos, momentos de tomada de decisão, flexibilização, dentre outros elementos que provocaram mudanças nos conhecimentos e nas concepções que essas licenciandas, ao longo da escolarização e da formação inicial, construíram sobre o aprender e o ensinar. Nesse percurso, as experiências pessoais, as experiências baseadas em conhecimento formal e as experiências vivenciadas na escola e na sala de aula reforçam o entendimento de que a identidade profissional docente 
que principia é uma construção individual, tendo como referência a história pessoal e suas características sociais, mas engloba, também, uma construção coletiva, derivada do contexto no qual a futura docente e/ ou o futuro docente se desenvolve (MARCELO; VAILLANT, 2012).

As análises das narrativas autobiográficas evidenciaram que a construção da identidade docente é caracterizada pelo retorno das licenciandas ao percurso de escolarização e formação inicial, estando presentes, nessas vivências, os ritos, as normas, a rigidez, os episódios significativos da relação entre docente e aluno e entre aluno e aluno; as lembranças provenientes da Língua Portuguesa e da Matemática; o choque com o "novo" contexto escolar, a opção pelo curso de Pedagogia, por ser professora; e os episódios que envolvem os familiares em seus trajetos escolares. Vale dizer que o contato direto que estabeleceram com a realidade da escola, contexto de suas futuras práticas, oportunizou um novo olhar sobre a futura profissão. As experiências escolares das futuras professoras, nos diversos níveis de ensino, tornaram-se espaços e tempos importantes para a aprendizagem da função docente e, consequentemente, para a constituição da identidade docente.

Na troca estabelecida colaborativamente com os participantes do curso, essas aprendizes de professoras já demonstram o conhecimento de algumas práticas educativas anteriores à formação acadêmica, as quais emergem nas narrativas autobiográficas: as imagens provenientes do militarismo na escola; os modelos e contramodelos de alguns professores; as metodologias de ensino que vivenciaram enquanto alunas; e, por fim, as marcas presentes nas narrativas, trazendo experiências importantes para o processo de vir a ser professoras, em que a identidade docente em construção se apresenta entre movimentos de pertença e de superação de identidades pressupostas.

Os dados analisados indicam, também, que as narrativas de formação e os pensamentos socializados pelos diálogos colaborativos estabelecidos nos fóruns dão lugar às novas experiências que emergem no próprio viver e fazer, em que as alunas-professoras se colocam para aceitar o imprevisto, o inusitado. As futuras professoras compreendem a necessidade de empreender novos estudos, demonstrando identidades em movimento e em tensão permanente, em que a interação entre elas e suas experiências individuais e profissionais está dentro de um continuum.

A análise interpretativa das narrativas das futuras professoras revela uma identidade docente em construção, em que é possível visualizar movimentos de pertença e de superação de identidades pressupostas, demonstrando estarem abertas às novas aprendizagens. 


\section{REFERÊNCIAS}

ALVES, F. C. Iniciação à docência: narrativas e experiências do Estágio Supervisionado e do Pibid. 168f. Dissertação (Mestrado) - Universidade do Estado da Bahia - UNEB, 2014.

ANDRÉ, M. Políticas de apoio aos docentes em estados e municípios brasileiros: dilemas na formação de professores. Educar em Revista - UFPR, Curitiba, Brasil, n. 50, p. 35-49, out./dez. 2013. Disponível em: <http://www.scielo.br/pdf/er/n50/n50a04.pdf> . Acesso em: 12 fev. 2015.

BORDENAVE, J. E. D. Alguns fatores pedagógicos. In: SANTANA, J. P.; CASTRO, J. L. (org.). Capacitação em desenvolvimento de recursos humanos - CADRHU. Natal: Ministério da Saúde; Organização Pan-Americana da Saúde; Editora da UFRN, 1999. p. 261-268.

CÂMARA, S. C. X.; PASSEGGI, M. C. Memorial autobiográfico: uma tradição acadêmica no Brasil. In: PASSEGGI, M. C.; VICENTINI, P. P.; SOUZA, E. C. (org.). Narrativas de si e formação. Curitiba: CRV, 2013.

CARDOSO, M. I. S. T.; BATISTA, P. M. F.; GRAÇA, A. B. S. A identidade do professor: desafios colocados pela globalização. Revista Brasileira de Educação, Rio de Janeiro, v. 21 n. 65, abr.-jun. 2016.

CASTRO, T. P. S. Construção automática de redes sociais móveis no ambiente moodle. 2012. 58f. Dissertação (Mestrado em Educação) - Universidade do Vale do Rio dos Sinos, São Leopoldo, Rio Grande do Sul, 2012.

CIAMPA, A. C. Identidade. A estória do Severino e a história da Severina. Um ensaio da Psicologia Social. São Paulo: Brasiliense, 2001.

CONTRERAS; J.; PÉREZ DE LARA, N. F. (Comp.). Investigar la experiência educativa. Madrid: Morata, p.15-19, 2010.

DAL-FORNO, J. P. Formação de formadores e educação inclusiva: análise de uma experiência via internet. 2009. 320f. Tese (Doutorado em Educação) - Universidade Federal de São Carlos, São Carlos, 2009.

DOMINICÉ, P. O processo de formação e alguns dos seus componentes relacionais. In: FINGER, M.; NÓVOA, A. O método (auto)biográfico e a formação. Natal, RN: EDUFRN; São Paulo: Paulus, 2010.

DUBAR, C. A socialização: construção das identidades sociais e profissionais. Trad. Andréa Stabel M. da Silva. São Paulo: Martins Fontes, 2005.

FERRAROTTI, F. Sobre a autonomia do método biográfico. In: NÓVOA, A.; FINGER, M. O método (auto)biográfico e a formação. Lisboa: MS/DRHS/CFAP, 2010. p. 31-58.

FERREIRA, A. A.; SILVA, B. D. Comunidade de prática on-line: uma estratégia para o desenvolvimento profissional dos professores de História. Educ. rev., Belo Horizonte, v. 30, n. 1, p. 37-64, mar. 2014. Disponível em: <http://www.scielo.br/scielo.php?script=sci_ arttext\&pid=S0102-46982014000100003\&lng=en\&nrm=iso > . Acesso em: 12 ago. 2015.

FLORES, M. A. La investigación sobre los primeros años de enseñanza: lecturas e implicaciones. In: MARCELO, C. (coord.). El profesorado principiante. Inserción a la docencia. Barcelona: Octaedro, 2009.

JOSSO, M. C. Experiências de vida e formação. Tradução José Cláudio e Júlia Ferreira. São Paulo: Cortez, 2004. 
JOSSO, M. C. Caminhar para si. Porto Alegre: EDIPUCRS, 2010.

KENSKI, V. M. Novos processos de interação e comunicação no ensino mediados pelas tecnologias. Cadernos Pedagogia Universitária, v. 7 - São Paulo: USP, 2008.

LARROSA, J. Notas sobre narrativa e identidade (a modo de presentación). In: ABRAHÃO, M. H. M. B. (org.). A aventura (auto)biográfica: teoria e empiria. Porto Alegre: EDIPUCRS, p. 11-27, 2004.

LARROSA, J. Herido de realidad y en busca de realidad. Notas sobre los lenguajes de la experiencia. In: CONTRERAS; J.; PÉREZ DE LARA, N. F. (comp.). Investigar la experiência educativa. Madrid: Morata, p.15-19, 2010.

LIMA, M. E. C. C.; GERALDI, M. G.; GERALDI, J. W. O Trabalho com narrativas na investigação em educação. Educ. rev., Belo Horizonte, v. 31, n. 1, p. 17-44, mar. 2015. Disponível em <http://www.scielo.br/scielo.php?script=sci_arttext\&pid=S010246982015000100017\&lng=pt\&nrm=iso $>$. Acesso em: 11 jul. 2015.

MARCELO, C. Formación del profesorado para el cambio educativo. $2^{\mathrm{a}}$ ed. Barcelona: EUB, 1999.

MARCELO, C. A identidade docente: constantes e desafios. Revista Brasileira de Pesquisa sobre Formação Docente, Belo Horizonte, v. 01, n. 01, p.109-131, ago./dez. 2009.

MARTINS, R. M. Aprendiz de professora: as narrativas sobre o processo de constituição da identidade docente dos licenciandos de matemática. 2012. 162f. Dissertação (Mestrado em Educação). Universidade Federal de Mato Grosso. Rondonópolis, 2012.

MARTINS, R. M. Aprendendo a ensinar: as narrativas autobiográficas no processo de vir a ser professora. 2015. 285f. (Doutorado em Educação). Universidade Federal de São Carlos. São Carlos, 2015.

MIZUKAMI, M. G. N. et al. Escola e aprendizagem da docência: processos de investigação e formação. São Carlos: EdUFSCar, 2003.

MOITA, M. C. Recursos de formação e de trans-formação. In: NÓVOA, A. (org.) Vida de professores. $2^{\mathrm{a}}$ ed. Portugal: Porto, p.111-140, 2000.

NACARATO, A. M.; PASSEGGI, M. C. Narrativas da experiência docente em matemática de professoras-alunas em um curso de pedagogia. In: SIMPÓSIO INTERNACIONAL DE ESTUDOS DE GÊNEROS TEXTUAIS - SIGET, 6., 16 a 19 de agosto de 2011, Natal. Anais... Natal, 2011. p. 1-14. Disponível em: <http://www.cchla.ufrn.br/visiget/ pgs/pt/anais/Artigos/ir\%20M. $\% 20$ Nacarato $\% 20$ (USF) $\% 20 \mathrm{e} \% 20$ Maria $\% 20 \mathrm{da} \% 20$ Concei $\%$ C3\%A7\%C3\%A3o\%20Passeggi\%20(UFRN).pdf>. Acesso em: 25 jul. 2013.

NÓVOA, A. Os professores e as histórias da sua vida. In: NÓVOA, A. (org.) Vida de professores. $2^{\mathrm{a}}$ ed. Portugal: Porto, p.11-30, 2000.

NÓVOA, A. Por que é que não fazemos aquilo que dizemos que é preciso fazer? In: CONGRESSO INTERNACIONAL SOBRE PROFESSORADO PRINCIPIANTE E INSERÇÃO PROFISSIONAL À DOCÊNCIA- IDEA, 4., 2014, Curitiba-PR. Anais...

OLIVEIRA, R. M. M. A. de. Narrativas na formação inicial em Pedagogia e na formação contínua de professores iniciantes. Projeto de Pesquisa. Financiamento CNPq, $\mathrm{N}^{\circ}$ Processo 401683/2011-7. São Carlos, 2011. 
PALACHI, W. B. L. Ações colaborativas universidade - escola: o processo de formação de professores que ensinam Matemática nos anos iniciais. 2011. 102f. Dissertação (Mestrado em Educação) - Pontifícia Universidade de São Paulo, São Paulo, 2011.

PLACCO, V. M. N. Souza; SOUZA, V. L. Trevisan. Identidade de professores: considerações críticas sobre perspectivas teóricas e suas possibilidades na pesquisa. In: CORDEIRO, A. F. M.; HOBOLD, M. S.; AGUIAR, M. A. L. de. (org.). Trabalho docente: formação, práticas e pesquisa. $2^{\text {a }}$ ed. Joinville-SC: Editora Univalle, p. 79-99, 2010.

REALI, A. M.; REYES, C. R. Reflexões sobre o fazer docente. São Carlos: EdUFSCar, 2009.

REALI, A. M.; TANCREDI, R. M.; MIZUKAMI, M. G. Programa de mentoria online: espaço para o desenvolvimento profissional de professoras iniciantes e experientes. Educação e Pesquisa, São Paulo, v.34, n.1, p.77-95, 2008.

RINALDI, R. P. Desenvolvimento profissional de formadores em exercício: contribuições de um programa online. 2009. 240f. Tese (Doutorado em Educação) Universidade Federal de São Carlos, São Carlos, 2009.

RODGERS, C. Defining reflection: Another look at John Dewey and reflective thinking. Teachers College Record, Columbia University, v.104, n.4, p. 842-866, 2002. Disponível em: < http://www. bsp.msu.edu/uploads/files/Reading_Resources/Defining_Reflection.pdf> $>$. Acesso em: 02 abr. 2013.

SANTOS. E. O. Ambientes virtuais de aprendizagem: por autorias livres, plurais e gratuitas. In: Revista FAEEBA, v.12, n. ${ }^{\circ}$ 18, 2003. Disponível em: < http://www.comunidadesvirtuais. pro.br/hipertexto/home/ava.pdf>. Acesso em: 04 nov. 2014.

SHULMAN, L. Conocimiento y enseñanza: fundamentos de la nueva reforma.). Profesorado. Revista de curriculum y formación del profesorado, Granada (Esp), v.9, n.2, 2005. Disponível em: < http://digibug.ugr.es/bitstream/10481/15244/1/rev92ART1.pdf>. Acesso em: 22 abr. 2013.

SILVA, I. A. Contribuições de um programa a distância sobre educação inclusiva para o desenvolvimento profissional do professor. 2012. 185f. Tese (Doutorado em Educação) - Universidade Federal de São Carlos. São Carlos, 2012.

SIMON, M. S. Inserção de professores iniciantes no campo profissional: um estudo de caso na escola básica. 2013. 211f. Tese (Doutorado em Educação) - Pontifícia Universidade Católica do Rio Grande do Sul, Porto Alegre, 2013.

SIMON, M. S. Inserção de professores iniciantes no campo profissional: um estudo de caso na escola básica. In: CONGRESSO INTERNACIONAL SOBRE PROFESSORES PRINCIPIANTES E INSERÇÃO PROFISSIONAL À DOCÊNCIA. Curitiba: UTFPR, 2014. Anais...

SOUZA, E. C. A arte de contar e trocar experiências: reflexões teórico-metodológicas sobre história de vida em formação. Revista Educação em Questão - EDUFRN, Natal, RN, v. 25, n. 11, p. 22-39, jan./abr. 2006. Disponível em: <http://www.revistaeduquestao.educ. ufrn.br/pdfs/v25n11.pdf>. Acesso em: 06 mai. 2013.

SOUZA, E. C. Histórias de vida e formação de professores. In: SOUZA, E. C. Histórias de vida e formação de professores. Salto para o Futuro. TV Escola, p.03-13, SEED-MEC. 2007a.

SOUZA, E. C. Memória e formação de professores. NASCIMENTO, A. D.; HETKOWSKI, T. M. (Org.) Memória e formação de professores [online]. Salvador: EDUFBA, 2007b. 310 p. ISBN 978-85-232-0484-6. Available from SciELO Books,. p. 58-74. Disponível em: <http://books.scielo.org>. Acesso em: 15 mai. 2008.

SOUZA, A. P. G. Contribuições da ACIEPE histórias infantis e Matemática na perspectiva de egressas do curso de Pedagogia. 2012. 246f. Tese (Doutorado em Educação). Universidade Federal de São Carlos. São Carlos, 2012. 
SOUZA, A. P. G. Diálogos cruzados sobre pesquisa (auto)biográfica: análise compreensivointerpretativa e política de sentido. Educação, Santa Maria, v. 39, n. 1, p. 39-50, jan./abr. 2014. ISSN: 0101-9031. Disponível em: <http://dx.doi.org/10.5902/1984644411344>. Acesso em: 23 set. 2014.

VAILLANT, D.; MARCELO, C. Ensinando a ensinar. As quatro etapas de uma aprendizagem. Curitiba: Ed. UTFPR, 2012.

ZEICHNER, K. M. Uma análise crítica sobre a "reflexão" como conceito estruturante na formação docente. Educ. Soc., Campinas, v. 29, n. 103, 2008. Disponível em: <http:// www.scielo.br/scielo.php?script $=$ sci_arttext\&pid=S0101-73302008000200012\&lng=en\&nr $\mathrm{m}=$ iso $>$. Acesso em: 22 abr. 2013.

ZEICHNER, K. M; SAUL, A.; DINIZ-PEREIRA, J. E. Pesquisar e transformar a prática educativa: mudando as perguntas da formação de professores - uma entrevista com Kenneth M. Zeichner. Revista e-Curriculum, São Paulo, v. 12, n. 03, p. 2211 - 2224, out./dez. 2014. ISSN: 1809-3876 2211 Programa de Pós-graduação Educação: Currículo - PUC/SP. Disponível em: <http://revistas.pucsp.br/index.php/curriculum>. Acesso em: 22 jul. 2015.

\section{NOTAS}

${ }^{1}$ Ver Shulman (2005).

${ }^{2}$ Infelizmente, no decorrer do curso, houve 47 desistências. Entre as justificativas, destacase: o excesso de atividades no dia a dia, impossibilitando o desenvolvimento das atividades, problemas pessoais e de saúde. Os trabalhos de Dal-Forno (2009), Rinaldi (2009) e Silva (2012) também apontaram índices semelhantes de evasão em cursos a distância.

${ }^{3} \mathrm{O}$ Moodle é uma plataforma de aprendizagem a distância baseada em software livre. É importante esclarecer que "o Moodle é adequado para atividades à distância, mas nada o impede de ser uma ferramenta para apoiar e complementar as atividades do ensino presencial" (CASTRO, 2012, p.26).

${ }^{4}$ Embora as histórias de formação profissional façam parte da história de vida dos sujeitos, optamos por separá-las, respaldadas na afirmação de Souza (2006, p.27) de que o termo "história de vida" revela o conhecimento de si e dos significados que atribuímos aos diferentes fenômenos que mobilizam e tecem a nossa vida individual e coletiva, porém, as "histórias de formação" abarcam todo o percurso de escolarização de professores e professoras em processo de formação.

Submetido: $30 / 11 / 2016$

Aprovado: 02/08/2017

Contato:

Departamento de Educação. Curso de Pedagogia Universidade Federal do Mato Grosso (UFMT) Campus Rondonópolis

Avenida dos Estudantes, 5055 - Bairro Cidade Universitária Rondonópolis $|\mathrm{MT}|$ Brasil CEP 78.736-900

E-mail: <rosanamariamartins13@gmail.com>. 